\title{
基 \\ Digestibilidade aparente da quirera e farelo de arroz para o tambaqui (Colossoma macropomum, Cuvier, 1818)
}

\author{
[Apparent digestibility of rice bran and broken rice for tambaqui \\ (Colossoma macropomum Cuvier, 1818]
}

\section{"Artigo Científico/Scientific Article"}

\author{
Priscila Monise Santos Santana ${ }^{1,2 *}$, Anailton Carlos Alves Almeida ${ }^{1,2}$, Ubatã Correa Pereira ${ }^{1,2}$, \\ Brenda Vieira Santos ${ }^{2}$, Jodnes Sobreira Vieira ${ }^{1,3}$, Carolina Nunes Costa Bomfim ${ }^{1,2}$
}

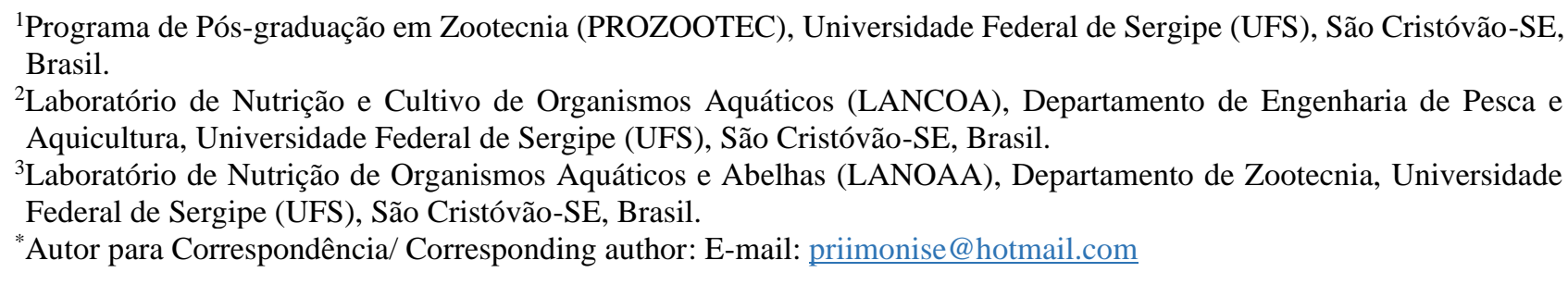

\section{Resumo}

Os coeficientes de digestibilidade aparente (CDA) de subprodutos do beneficiamento do arroz (farelo e quirera de arroz) foram estimados para o tambaqui (Colossoma macropomum). Juvenis com peso médio de 63,5 $\mathrm{g} \mathrm{(} \pm$ $2,7 \mathrm{~g}$ ) foram distribuídos em tanques de fundo cônico com capacidade de $100 \mathrm{~L}$. Uma dieta referência foi formulada de acordo com as exigências nutricionais do tambaqui, enquanto duas dietas-teste foram constituídas de $70 \%$ da dieta referência e $30 \%$ de farelo ou quirera de arroz, sendo incorporado $0,5 \%$ de óxido de cromo como marcador externo. A determinação do CDA foi realizada pelo método de Guelph modificado com a coleta das excretas por sedimentação e quantificação do óxido de cromo. Os CDAs da matéria seca (MS), proteína bruta $(\mathrm{PB})$, extrato etéreo $(\mathrm{EE})$, fibra bruta $(\mathrm{FB})$ e energia bruta $(\mathrm{EB})$ da dieta referência foram 71,$7 ; 88,9 ; 86,1 ; 42,6$ e 91,6\%, respectivamente. Os CDAs da dieta com o farelo de arroz foram semelhantes à da dieta referência (MS, 72,6\%; $\mathrm{PB}, 90,2 \%$; $\mathrm{EE}, 86,0 \%$; $\mathrm{FB}, 48,8 \%$ e $\mathrm{EB}, 86,1 \%)$. A dieta com quirera apresentou CDAs de $74,3 \%$ para MS, 88,2\% para PB; 82,8\% para EE, 55,7\% para FB e $84,1 \%$ para EB. O farelo e a quirera de arroz foram altamente digeridos pelo tambaqui, podendo ser utilizados como ingredientes em dietas para essa espécie.

Palavras-chave: alimento alternativo; digestibilidade; subprodutos do arroz.

\begin{abstract}
The apparent digestibility coefficients (CDA) of rice byproducts (rice bran and broken rice) were estimated for the tambaqui (Colossoma macropomum). Juveniles with a mean weight of $63.5 \mathrm{~g}( \pm 2.7)$ were distributed in conical bottom tanks with a capacity of $100 \mathrm{~L}$. A reference diet was formulated according to the nutritional requirements of tambaqui, while two test diets consisted of $70 \%$ of the reference diet and $30 \%$ of rice bran or broken rice, with $0.5 \%$ of chromium oxide being incorporated as an external marker. Determination of CDAs was performed by the Guelph method modified with excreta collection by sedimentation and quantification of chromium oxide. The dry matter (DM), crude protein (CP), ethereal (EE), crude fiber (FB) and crude energy (BW) of the reference diet were $71.7 ; 88.9 ; 86.1 ; 42.6$ and $91.6 \%$, respectively. The dietary CDAs with rice bran were similar to those of the reference diet (MS, 72.6\%, CP, 90.2\%, EE, 86.0\%, FB, 48.8\%, and EB, 86.1\% $\%$ ). The diet with broken rice presented CDAs of $74.3 \%$ for MS, $88.2 \%$ for PB; $82.8 \%$ for EE, $55.7 \%$ for FB, and $84.1 \%$ for EB. Rice bran and broken rice were highly digested by tambaqui and could be used as ingredients in diets for this species.
\end{abstract}

Keywords: alternative feeds; digestibility; rice byproducts. 


\section{Introdução}

Com a redução dos estoques naturais de pescados, a piscicultura tornou-se a principal alternativa sustentável para suprir as demandas do mercado consumidor (BRASIL, 2011). O tambaqui, Colossoma macropomum (Cuvier, 1818), é o segundo peixe mais produzido atualmente no Brasil. O crescimento da produção dessa espécie se justifica pela adaptação ao cativeiro, facilidade de obtenção de juvenis, potencial de crescimento, rusticidade no manejo e a fácil adaptação às rações comerciais (Faria et al., 2013).

O hábito alimentar do tambaqui é definido como onívoro-oportunista. A dieta natural é composta preferencialmente por sementes e frutos no período de cheia dos rios, o que caracteriza uma maior ingestão de carboidratos e fibras e no período de seca aumenta o consumo de alimentos de origem animal e outros itens alimentares, como macrófitas, insetos, algas, moluscos e peixes (Rodrigues, 2014).

O conhecimento sobre o tipo de alimentação e das exigências nutricionais das espécies de cultivo é fundamental para elaboração de dietas balanceadas que permitam máxima resposta produtiva, proporcione saúde aos peixes e minimize impactos ambientais (Dairiki, 2011). Os gastos com alimentação podem representar até $60 \%$ do custo de produção, sendo que o preço da ração se eleva de acordo com o teor de proteína nela contido. $O$ valor nutritivo de uma ração não depende apenas do teor de nutrientes, mas também da capacidade do animal em digerir e assimilar o alimento (Bezerra et al., 2014).

É necessário ter uma alimentação que atenda às exigências nutricionais aliados a boas práticas de manejo que visem diminuir esses custos, bem como o uso de ingredientes alternativos que venham a minimizar as despesas com ração. Uma forma de diminuir os custos da ração seria a utilização de ingredientes diferentes aos tradicionalmente usados, mas que apresentem o mesmo valor nutricional e atendam às exigências do animal (Lima et al., 2011; Carvalho et al., 2012).

$O$ fornecimento de uma alimentação adequada deve estar de acordo com a exigência nutricional de cada espécie e uma das formas de se avaliar é através de estudos que estimem o grau de digestibilidade e consequentemente, assimilação dos nutrientes pelos peixes. E assim viabilizar a inclusão de subprodutos da agroindústria que podem funcionar como uma fonte de nutrientes de baixo custo, quais são desperdiçados na maioria das vezes (Glencross et al., 2007).

Dentre desses subprodutos com grande potencial para o aproveitamento na alimentação animal são os provenientes do beneficiamento do arroz (Oryza sativa), possuindo em sua composição vitaminas, minerais e fibras, fazendo deles uma boa opção como ingrediente alternativo. Tanto a quirera e o farelo de arroz têm uma alta disponibilidade no mercado (Ribeiro et al., 2010). $\mathrm{O}$ presente trabalho teve como objetivo determinar o coeficiente de digestibilidade aparente da quirera e farelo de arroz para o tambaqui $(C$. macropomum).

\section{Material e Métodos}

O estudo foi conduzido na Unidade de Aquicultura (UNIAQUA), no Campus rural da Universidade Federal de Sergipe, São Cristóvão, SE. Foram utilizados 24 juvenis de tambaqui com peso médio inicial médio de 63,5 $\pm 2,7 \mathrm{~g}$, fornecidos pela $5^{\text {a }}$ Estação de Piscicultura da Companhia de Desenvolvimento dos Vales do São Francisco e Parnaíba (Companhia de Desenvolvimento dos Vales do São Francisco e do Parnaíba-CODEVASF)-, os quais foram aclimatados nas condições experimentais por 10 dias.Utilizou-se um delineamento em blocos casualizados com três tratamentos e três repetições por tempo, durante 60 dias. A estrutura física foi formada por três tanques de digestibilidade de fundo cônico com capacidade de $100 \mathrm{~L}$, adequados para o método Guelph modificado. Este sistema estava equipado com filtragem biológica e aeração constante foi adaptada no interior de cada tanque, um sistema de contenção de ração constituído por um prato plástico que também serviu como vedação, auxiliando na ingestão das rações pelos peixes e impedindo que as mesmas descessem para o fundo cônico do tanque. Diariamente eram medidas a temperatura e oxigênio dissolvido da água (oxímetro digital, Instrutherm MO-0910, SP, Brasil). $\mathrm{O} \mathrm{pH}$ e as concentrações de amônia e nitrito eram medidos a cada três dias através de kit colorimétrico (Alfakit, Florianópolis, SC, Brasil). Para as coletas de fezes, a metodologia adotada foi por sedimentação pelo sistema de Guelph modificado, conforme Abimorad e Carneiro (2004).

Foram elaboradas três dietas experimentais (Tabela 1), sendo uma dieta referência e duas contendo os ingredientes a serem testados. Os 
ingredientes previamente moídos em moinho tipo facas, com peneira de $1,0 \mathrm{~mm}$, foram misturados, umedecidos com água a $65^{\circ} \mathrm{C}$, para em seguida serem peletizados em moedor do tipo industrial (Becker - PEC-09, SP, Brasil). Após a peletização, as dietas foram acondicionadas em bandejas metálicas para a secagem em estufa de ventilação forçada a $55^{\circ} \mathrm{C}$, por $24 \mathrm{~h}$. A dieta referência foi formulada com $30 \%$ de PB e $3200 \mathrm{kcal} / \mathrm{kg}$ de energia bruta, de acordo com a exigência nutricional da espécie, e as dietas teste (farelo e quirera de arroz) na proporção de $70 \%$ da dieta referência e 30\% do ingrediente teste, acrescidas de $0,5 \%$ de óxido de cromo como indicador em todas as dietas.

Tabela 1. Composição percentual e bromatológico das dietas experimentais.

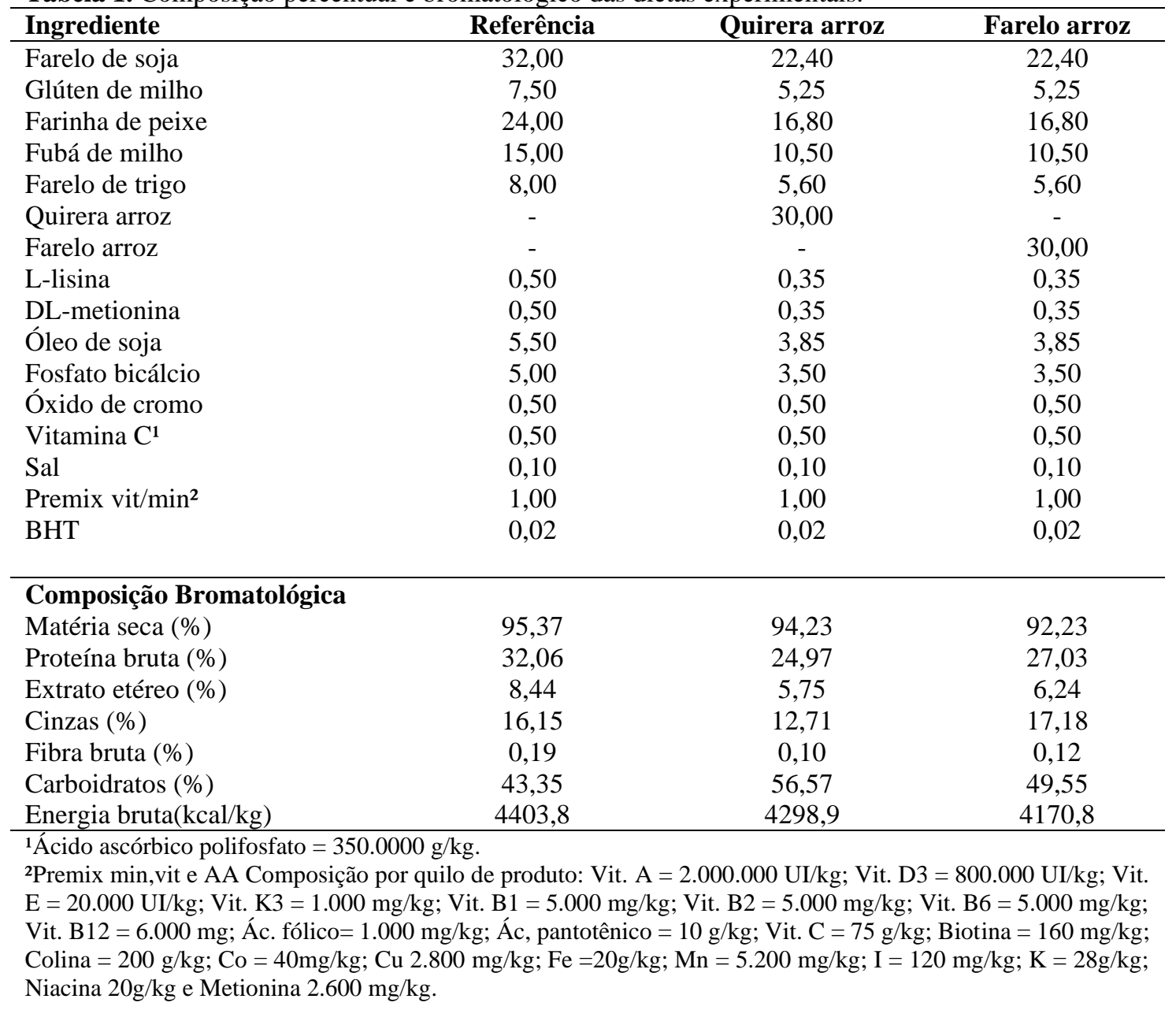

$\mathrm{O}$ arraçoamento aconteceu até saciedade aparente duas vezes ao dia, às $9 \mathrm{~h}$ e $15 \mathrm{~h}$. Os peixes foram mantidos nos tanques, e após o último arraçoamento do dia, cada tanque era escovado e $30 \%$ do volume de água era renovado. O tubo coletor era então colocado no fundo do tanque. A coleta das fezes, iniciadas após o $5^{\circ}$ dia de alimentação, foram realizadas no início da manhã através da retirada do coletor. As fezes foram submetidas à secagem em estufa com ventilação forçada de ar $\left(55^{\circ} \mathrm{C}\right)$, por $24 \mathrm{~h}$, e em seguida submetidas às análises químicas.

Foi analisada a composição química bromatológica dos subprodutos do beneficiamento de arroz (Tabela 2), dietas experimentais e das fezes, em que foram determinados a matéria seca (MS) por secagem em estufa, matéria mineral (MM) pela incineração em mufla, proteína bruta (PB) por meio do método de micro Kjeldahl, fibra bruta (FB) com um digestor de fibra, extrato etéreo (EE) por Soxhlet. Todos os métodos foram realizados de acordo com a AOAC (2000) e descritos por Silva e Queiroz (2002). A energia bruta $(\mathrm{kcal} / \mathrm{g})$ das amostras (subprodutos, dietas experimentais e fezes) foi medida em bomba calorimétrica (modelo Ika 200, Staufen, Alemanha) e os teores de carboidratos totais (CT) foram determinados segundo Sniffen et et al. (1992), utilizando-se a equação: $\mathrm{CT}=100-(\% \mathrm{~PB}$ $+\% \mathrm{EE}+\%$ cinzas $)$. 
A determinação do teor de cromo nas fezes foi realizada em espectrofotômetro de absorção atômica (mod. Feixe UV-M51, Piracicaba, SP). A determinação foi realizada de modo a atender os limites de detecção para o óxido de cromo $\left(\mathrm{Cr}_{2} \mathrm{O}_{3}\right)$ nas fezes, segundo Furukawa e Tsukahara (1976).

Tabela 2. Composição bromatológica (\%) da quirera e farelo de arroz, subprodutos do beneficiamento de arroz.

\begin{tabular}{lccccccc}
\multicolumn{2}{c}{ arroz. } & \multicolumn{1}{c}{ PB } & EE & FB & MM & EB & CHO \\
\hline Ingredientes & MS & & & & & & \\
Quirera & 94,60 & 8,97 & 1,16 & 0,90 & 0,67 & $4.112,33$ & 89,2 \\
Farelo & 95,29 & 10,95 & 14,13 & 0,12 & 5,82 & $4.907,98$ & 69,1 \\
\hline
\end{tabular}

MS = Matéria seca, PB = Proteína bruta, EE = Extrato etéreo, FB = Fibra bruta, MM =Material mineral,

$\mathrm{EB}=$ Energia bruta $\left(\mathrm{em} \mathrm{kcal} \mathrm{kg}^{-1}\right), \mathrm{CHO}=$ carboidratos.

O coeficiente de digestibilidade aparente (CDA) das dietas foram calculados pela equação de Cho e Slinger (1979):

$\mathrm{CDA}(\%)=100-\{100 *[((\% \mathrm{Cr} 2 \mathrm{O} 3 \mathrm{~d} / \% \mathrm{Cr} 2 \mathrm{O} 3 \mathrm{f}) *(\%$ $\mathrm{N} \mathrm{f} / \% \mathrm{~N} \mathrm{~d}))]\}$

Em que:

CDA $(\%)=$ coeficiente de digestibilidade do nutriente/ energia;

$\% \mathrm{Cr}_{2} \mathrm{O}_{3} \mathrm{~d}=\%$ de óxido de cromo na dieta;

$\% \mathrm{Cr}_{2} \mathrm{O}_{3} \mathrm{f}=\%$ óxido de cromo nas fezes;

$\mathrm{Nf}=$ nutriente/ energia nas fezes; $\mathrm{Nd}=$ nutriente/ energia na dieta.

Para o cálculo da digestibilidade aparente da MS, PB, EE, FB e EB dos ingredientes testados, foi utilizada a seguinte equação, de acordo com Reigh et al. (1994):

DAN $(\%)=(100 / 30) \times$ [teste $-(70 / 100 \times$ referência)]

Em que:

DAN = digestibilidade aparente do nutriente ou da energia do alimento;

Teste $=$ digestibilidade aparente do nutriente ou da energia presente na dieta-teste;

Referência $=$ digestibilidade aparente do nutriente ou da energia presente na dieta referência.

A análise estatística dos resultados foi realizada por meio do software SISVAR - versão 5.6, conforme descrito por Ferreira (2011). As médias foram submetidas à análise de variância (ANOVA), e foi realizada a comparação de médias pelo teste de Tukey a 5\% de significância.

\section{Resultados e Discussão}

Durante o período experimental, as médias ( \pm DP) das variáveis físico-químicas da água nos tanques foram: temperatura de $27,4^{\circ} \mathrm{C}( \pm 0,5), \mathrm{pH}$
$6,39$ ( $\pm 0,66)$ e a concentração de oxigênio dissolvido foi $6,69 \mathrm{mg} / \mathrm{L}( \pm 0,70)$. Estes valores estão dentro da faixa considerada aceitável para o cultivo do tambaqui e provavelmente não tenham influenciado os resultados do presente estudo. Qualquer alteração dessas variáveis poderia prejudicar os animais (Faria et al., 2013).

O grão de arroz polido é considerado uma fonte de carboidratos, sendo constituído principalmente de amido. No entanto, apresentam ainda em sua constituição proteína, vitaminas, sais minerais e fibras (Naves, 2007). O farelo e a quirera (Tabela 2), possuem alto teor de carboidratos (89,7 e $69,1 \%$, respectivamente) e baixo teor de proteína bruta (10,95 e 8,97\%, respectivamente), caracterizando-os como alimentos energéticos. Estes ingredientes são considerados como tendo potencial para utilização em rações de animais (Lacerda et al., 2010).

O teor de extrato etéreo do farelo de arroz foi $14,13 \%$, corroborando ao descrito no NRC (2011). $\mathrm{O}$ alto teor de extrato etéreo presente no farelo de arroz é resultado do processamento do endosperma, em que há alteração do teor de amido com os resíduos da casca, afetando a quantidade de lipídios no farelo (Lacerda et al., 2010). Esse alto teor de extrato etéreo não comprometeu a digestibilidade do farelo de arroz, com valor de DAN 81,28\%. Esse teor foi superior ao DAN EE da quirera de arroz $(72,76 \%)$, que apresenta na sua composição bromatológica $1,36 \%$, valor menor que $\mathrm{o}$ farelo de arroz. $\mathrm{O}$ farelo representa aproximadamente 5-8\% do total do grão de arroz, sendo consideradas umas das partes mais nutritivas do grão (Silva et al., 2006).

Os valores de matéria seca e matéria seca digestível do farelo de arroz (DAN 74,70 e VD $71,18 \%$ ) e quirera (DAN 74,36 e VD 70,34\%) são superiores aos encontrados por Furuya (2008) para a tilápia do Nilo, em que os teores de matéria seca 
total (VD) foram estimados em 51,01\%. Nesse mesmo contexto se encontra os teores de energia bruta descrito no presente trabalho para farelo de arroz foi de $4907,98 \mathrm{kcal} / \mathrm{kg}$ e para energia digestível $3597,54 \mathrm{kcal} / \mathrm{kg}$, valores estão similares aos descritos por Furuya (2008), para tilápia do Nilo que foi 4098,00 kcal/kg, energia digestível de $2359,63 \mathrm{kcal} \mathrm{kg}$. As proximidades dos valores observados podem ser atribuídas ao hábito alimentar e às condições nutricionais das espécies.
A tilápia e o tambaqui são onívoros com eficiência semelhante na habilidade e assimilação do alimento.

Os valores de DAN do farelo e quirera foram altos para proteína 92,97 e 83,24\%, respectivamente, demonstrando um alto aproveitamento dos ingredientes testados pelos tambaquis, e consequentemente, valores digestíveis próximos aos valores brutos (Tabela 3).

Tabela 3. Valores totais (Total), digestibilidade aparente (DAN) e valores digestíveis (VD) de matéria seca $(\mathrm{MS})$, proteína $(\mathrm{P})$, fibra $(\mathrm{F})$, extrato etéreo $(\mathrm{EE})$ e energia $(\mathrm{E})$ do farelo de arroz e quirera de arroz (base na matéria seca).

\begin{tabular}{lcccccc}
\hline & \multicolumn{3}{c}{ Farelo de arroz } & \multicolumn{3}{c}{ Quirera } \\
\hline Nutriente & Total & DAN & VD & Total & DAN & VD \\
MS (\%) & 95,29 & 74,70 & 71,18 & 94,60 & 74,36 & 70,34 \\
Proteína (\%) & 10,95 & 92,97 & 10,18 & 8,97 & 83,24 & 7,46 \\
EE (\%) & 14,13 & 81,28 & 11,48 & 1,36 & 72,76 & 0,98 \\
Fibra (\%) & 0,12 & 52,54 & 0,06 & 0,90 & 81,89 & 0,70 \\
*Energia (Kcal kg-1) & 4907,98 & 73,30 & 3597,54 & 4112,33 & 69,84 & 2872,05 \\
\hline
\end{tabular}

Os coeficientes de digestibilidade aparente das dietas (CDA) da matéria seca (MS), proteína bruta (PB), extrato etéreo (EE), fibra bruta (FB) e energia bruta (EB) para o farelo de arroz e quirera de arroz encontram-se na (Tabela 4). Houve apenas diferença estatística entre os valores de CDA das dietas experimentais para energia bruta, a quirera de arroz apresentou menor valor de CDA 84,07\%, quando comparados a dieta referência e a de farelo de arroz. Os demais resultados ficaram entre $72 \%$ matéria seca, $91 \%$ proteína, $86 \%$ extrato etéreo,
$55 \%$ fibra e $91 \%$ energia bruta. Esses valores foram superiores aos valores encontrados por Abimorad e Carneiro (2004) para o pacu (Piaractus mesopotamicus), em que a dieta referência e a dieta com o farelo de arroz integral, obtiveram os CDA de EB de $(63,55$ e $65,83 \%$, respectivamente). Em ambos os resultados houve similaridade entre a dieta referência e o farelo de arroz. Este resultado pode ser explicado pelo menor valor energético da ração referência com relação à ração com farelo de arroz.

Tabela 4. Coeficiente de digestibilidade aparente da matéria seca, proteína bruta, extrato etéreo, fibra bruta e energia bruta das dietas experimentais.

\begin{tabular}{lccccc}
\hline \multicolumn{5}{c}{ Coeficiente de digestibilidade aparente (\%) } \\
\hline Ração & MS & PB & EE & FB & EB \\
Referência & $71,70 \pm 3,46^{\mathbf{a}}$ & $88,95 \pm 0,85^{\mathbf{a}}$ & $86,06 \pm 1,90^{\mathbf{a}}$ & $42,59 \pm 6,40^{\mathbf{a}}$ & $91,62 \pm 1,22^{\mathbf{a}}$ \\
Farelo de arroz & $72,60 \pm 2,94^{\mathbf{a}}$ & $90,16 \pm 1,18^{\mathbf{a}}$ & $86,04 \pm 3,97^{\mathbf{a}}$ & $48,78 \pm 5,92^{\mathbf{a}}$ & $86,13 \pm 1,01^{\mathbf{a}}$ \\
Quirera & $74,27 \pm 0,78^{\mathbf{a}}$ & $88,17 \pm 1,23^{\mathbf{a}}$ & $82,07 \pm 2,79^{\mathbf{a}}$ & $55,67 \pm 0,52^{\mathbf{a}}$ & $84,07 \pm 3,31^{\mathbf{b}}$ \\
\hline
\end{tabular}

MS = Matéria Seca, PB = Proteína Bruta, EE = Extrato Etéreo, FDN = Fibra bruta e EB= Energia bruta.

Médias seguidas de letras iguais nas colunas não diferem entre si, pelo teste de Tukey, em nível de $5 \%$ de significância $(\mathrm{P}<0,05)$.

Os menores valores de coeficiente de digestibilidade observados no presente estudo é o CDA FB que está entre 55,67 a 42,59\%, esses baixos valores podem ser por decorrência do efeito dos polissacarídeos não amiláceos, que tende a aumentar a viscosidade do bolo alimentar e interferir negativamente na velocidade de trânsito alimentar, diminuindo a digestibilidade (Borghesi et al. 2009; Chowdhury et al. 2012). Vieira (2007), avaliando diferentes variedades de subprodutos de arroz, concluiu que a fibra alimentar presente no farelo é constituído basicamente por hemicelulose, com alta capacidade de retenção de água, e por lignina, que é considerada indigestível. Devido à ausência de padronização no processamento, a composição química do farelo de arroz pode apresentar grande variação nos resultados.

Teixeira et al. (2010), em outro estudo com farelo de arroz testado para o surubim (Pseudoplatystoma fasciatum) e pintado 
(Pseudoplatystoma corruscans), encontraram valores de CDA para matéria seca de 59,67\%, CDA para energia bruta de $66,41 \%$, e na quirera de arroz, o CDA para matéria seca de $40,39 \%$ e CDA para energia bruta de 45,92\%, inferiores aos encontrados no presente estudo. Esses valores baixos podem ser justificados por tratar de espécies com hábito alimentar carnívoro, que diferem dos peixes onívoros em vários aspectos, como a anatomia do trato digestório e fisiologia digestiva, habilidade e capacidade absortiva de nutrientes, e da disponibilidade de enzimas presentes no sistema digestório. Em peixes carnívoros, a secreção da amilase se restringe apenas ao pâncreas, enquanto que a síntese da amilase em espécies onívoras ocorre no pâncreas e em toda a mucosa intestinal, no qual a maior concentração dessa enzima permite um melhor aproveitamento de carboidratos presentes em alimentos de origem vegetal (Gonçalves et al., 2013).

Guimarães et al. (2008), testaram dois ingredientes farelo de arroz e farelo de trigo, o DAN determinado para os peixes alimentados com o farelo de arroz (MS 55,59 e EB 57,58\%), foi similar ao CDA para o farelo de trigo (MS 45,88 e EB 48,94\%). Os subprodutos de arroz aparecem como um dos ingredientes para o uso em dietas de tilápia do Nilo por causa dos seus altos valores de digestibilidade de nutrientes, quando comparados as outras fontes energéticas.

$\mathrm{Na}$ avaliação de diferentes fontes de amido (farelo de trigo, farelo de mandioca, milho moído e quirera de arroz) na alimentação de jundiá, foi possível notar valores intermediários de DAN digestibilidade da quirera de arroz (EB 64,0848,05\%), (MS 55,05-60,5\%), esses valores foram inferiores ao presente trabalho (EB 69,84\%) e (MS $74,36 \%$ ). Embora as espécies possuam o mesmo hábito alimentar onívoro, o jundiá mostrou menor capacidade de digestão, para quirera de arroz com relação ao tambaqui. Essas diferenças nos resultados reforçam que apesar de possuir o mesmo hábito alimentar onívoro, as espécies possuem suas particularidades e suas próprias adaptações fisiológicas (Oliveira e Fracalossi, 2006; GominhoRosa, et al. 2015).

É de grande importância, ao substituir alimentos convencionais por alternativos, que seja realizada a análise química do alimento para verificar seu potencial nutricional, utilizar produtos que não tenham sazonalidade, e que seja produzido em grandes quantidades, de fácil processamento, armazenamento, baixo custo quando comparados aos convencionais, e que o desempenho dos animais seja semelhante ou superior aos daqueles alimentados com rações elaboradas utilizando-se ingredientes tradicionais (Torelli et al., 2010).

Diante dos resultados com altos valores de coeficiente de digestibilidade aparente determinados e altos teores digestíveis para os nutrientes estudados, conclui-se que o tambaqui apresentou alta capacidade de digerir farelo e a quirera de arroz.

\section{Conflito de Interesse}

Os autores declaram não existir conflito de interesse.

\section{Comitê de Ética}

Todos os procedimentos experimentais foram autorizados pelo Comitê de ética no uso de animais da Universidade Federal de Sergipe (CEUA/CEPAP-UFS, 02/2016).

\section{Agradecimentos}

À Fundação de Apoio à Pesquisa e à Inovação Tecnológica do Estado de Sergipe pela bolsa de estudos. Ao Programa de Estímulo a Mobilidade (PROMOB) pelos recursos cedidos ao PROZOOTEC. À Pratigi Alimentos pela doação dos ingredientes. À Companhia de Desenvolvimento dos Vales do São Francisco e do Parnaíba pela doação dos juvenis de tambaqui. O presente trabalho foi realizado com apoio da Coordenação de Aperfeiçoamento de Pessoal de Nível Superior - Brasil (CAPES) - Código de Financiamento 001.

\section{Referências}

Abimorad, E.G.; Carneiro, D. J. Métodos de coleta de fezes e determinação dos coeficientes de digestibilidade da fração proteica e da energia de alimentos para o pacu, (Piaractus mesopotamicus, Holmber, 1887). Revista Brasileira de Zootecnia, 33(315): 11011109, 2004.

Association of official analytical chemistis AOAC. Official Methods of Analysis, 2000.

Bezerra, S.K.; Souza, R.C.; Melo, J.F.B.; Campeche, D.F.B. Crescimento de tambaqui alimentado com diferentes níveis de farinha de manga e proteína na ração. Archivos de zootecnia, 63: 244-588, 2014.

Borghesi, R.; Dairiki, J.K.; Cyrino, J.E.P. Apparent digestibility coefficients of selected feed 
ingredients for dourado Salminus brasiliensis. Aquaculture Nutrition, 15: 453-458, 2009.

BRASIL. Ministério da Pesca e Aquicultura. 2011.

Boletim Estatístico da Pesca e Aquicultura - Brasil - 2011. Brasília. Disponível em: http://www.icmbio.gov.br/cepsul/images/stor ies/biblioteca/download/estatistica/est_2011_ bol_bra.pdf. Acesso em: 12 abril. 2017.

Carvalho, P.L.P.F.; Silva, R.L.; Botelho, R.M.; Damasceno, F.M.; Rocha, M.K.H.R.; Pezzato, L.E. Valor nutritivo da raiz e folhas da mandioca para a tilápia do Nilo. Boletim do Instituto de Pesca, 38 (1): 61-69, 2012.

Cho, C.Y.; Slinger, S.J. Apparent digestibility measurements in feedstuffs for rain bow trout. In: Halver, J.E.; Tiews. Finfish nutrition and fish feed technology, 1979. 239-247p.

Chowdhury, M.A K.; Tacon, A.G.J.; Bureau, D.P. Digestibility of amino acids in Indian mustard protein concentrate and Indian mustardmeal comparedto that of a soy protein concentrate in rain bow trout and Atlantic salmon. Aquaculture, 356: 128-13, 2012.

Dairiki, J. K. Exigências nutricionais do tambaqui. Embrapa Amazônia Ocidental, Manaus: Embrapa, 2011. 336p.

Faria, R.H.S.A.; Morais, M.; Soranna, M.R.G.S.; Sallum, W.B. Manual de criação de peixes em viveiros. Brasília: Codevasf, 2013.136p.

Ferreira, D. F. Sisvar: a computer statistical analysis system. Ciência e Agrotecnologia Universidade Federal de Lavras, 35(6): 10391042, 2011.

Furukawa, A.; Tsukahara, H. On the acid digestion for the determination of chromic oxide as index substance in the study digestibility of fish feed. Bulletin of the Japanese Society of Fisheries, 32(6): 502-506, 1976.

Furuya, W.M.; Fujii, K.M.; Santos, L.D.; Silva, T.S.C.; Silva, L.C.R.; Sales, P.J.P. Exigência de fósforo disponível para juvenis de tilápiado-nilo. Revista Brasileira de Zootecnia, 37(9):1517-1522, 2008.

Glencross, B. D.; Booth, M.; Allan, G.L. A feed is only as good as its ingredients - a review of ingredient valuation strategies for aquaculture feeds. Aquaculture Nutrition, 13: 17-34, 2007.

Gominho-Rosa, M.C.; Rodrigues, A.P.O.; Mationi, B.; Francisco, A.de; Moraes, G.; Fracalossi, D.M. Comparison between the omnivorous jundiá catfish (Rhamdia quelen) and Nile tilapia (Oreochromis niloticus) on the utilization of dietary starch sources: Digestibility, enzyme activity and starch microstructure. Aquaculture, 435: 92-99, 2015.

Goncalves, L.U.; Rodrigues, A.P.O.; Moro, G.V.; Ferreira, E.C.; Cyrino, J.E.P. Morfologia e Fisiologia do Sistema Digestório de Peixes. Nutriaqua. In: Fracalossi, D.M.; Cyrino, J.E.P. Florianópolis: Aquabio, 2012. p. 9-36.

Guimarães, I.G.; Pezzato, L.E.; Barros, M.M.; Tachibana, L. Nutrient digestibility of cereal grain products and by-products in extruded diets for Nile tilapia. Journal of the World Aquaculture Society, 39(6): 781-789, 2008.

Lacerda, D.B.C.L.; Júnior, M.S.S.; Bassinellop. Z.; Castro, M.V.L.; Silva, V.L. et al. Qualidade de farelo de arroz cru extrusado e parboilizado. Pesquisa Agropecuária Tropical, 40 (4): 521-530, 2010.

Lima, M.R.; Ludke, M.C.M.M.; Porto-Neto, F.F.; Pinto, B.W.C.; Torres, T.R.; Souza, E.J.O. Farelo de resíduo de manga para tilápia do Nilo. Acta Scientiarum. Animal Sciences, 33 (1): 65-71, 2011.

Naves, M.M.V.; Características químicas e nutricionais do arroz. Boletim do Centro de Pesquisa e Processamento de Alimentos, 25(1):51-60,2007.

NRC - Nutrient Research Council: nutrient requirements of fish and shrimp. Washington: The National Academies Press, 2011. 376p.

Oliveira, F.P.R.C.; Fracalossi, D.M. Coeficientes de digestibilidade aparente de ingredientes para juvenis de jundiá. Revista Brasileira de Zootecnia, 35 (4): 1581-1587, 2006.

Reigh, R.C.; Braden, S.L.; Craig, R.J. Apparent digestibility coefficients for common feed in formulated diets for tropical cratfish, Mystus nemurus (Cuvier \& Valenciennes). Aquaculture, 84: 321-334, 1994.

Ribeiro, A. M. L.; Henn, J. D.; Silva, G. L. Alimentos alternativos para suínos em crescimento e terminação. Acta Scientiae Veterinariae, 38 (1): 61-67, 2010.

Silva, D. J.; Queiroz, A. C. de. Análise de alimentos: métodos químicos e biológicos UFV. Viçosa: Universidade Federal de Viçosa, 2002, 235p.

Silva, M. A.; Sanches, C.; Amante, E. R. Prevention of hydrolytic rancity in rice bran. Journal of Food Engineering, 75: 487-491, 2006. 
Sniffen, C.J., O’connor, J.D., Van Soest, P.J., Fox, D.G., Russell, J.B. A net carbohydrate and protein system for evaluating cattle diets. II. Carbohydrate and protein availability. Journal Animal Science, 70 (11): 35623577, 1992.

Teixeira, E.A.; Saliba, E.O.S.; Euler, A.C.C.; Faria, P.M.C.; Crepaldi, D.V.; Ribeiro, L.P. Coeficientes de digestibilidade aparente de alimentos energéticos para juvenis de surubim. Revista Brasileira de Zootecnia, 39(6): 1180-1185, 2010.
Torelli, J.E.R.; Oliveira, E.G.; Hipólito, M.L.F.; Ribeiro, L.L. Uso de resíduos agroindustriais na alimentação de peixes em sistema de policultivo. Revista Brasileira de Engenharia de Pesca, 5(3): 1-15, 2010.

Vieira, A.R.; Rabello, C.B. R; Mohaupt, M.C.; Dutra Júnior. W.M.; Torres, D.M.; Lopes, J.B. Efeito de diferentes níveis de inclusão de farelo de arroz em dietas suplementadas com fitase para frangos de corte. Acta Scientiarum. Animal Science, 29 (3): 267 275, 2007. 